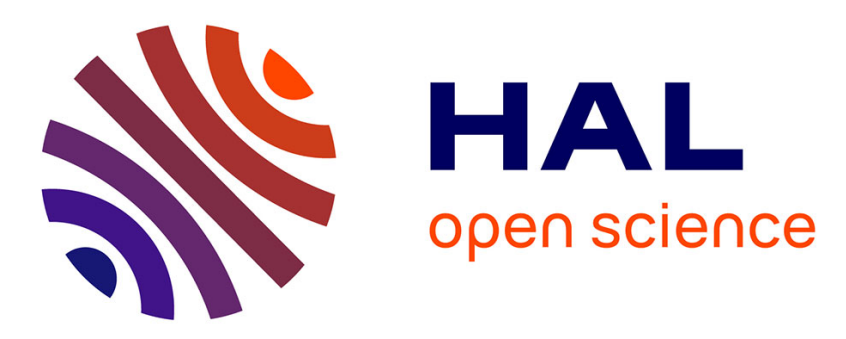

\title{
A connected soil humidity and salinity sensor for precision agriculture
}

Julien Roux, Jean-Yves Fourniols, Georges Soto-Romero, Christophe Escriba

\section{To cite this version:}

Julien Roux, Jean-Yves Fourniols, Georges Soto-Romero, Christophe Escriba. A connected soil humidity and salinity sensor for precision agriculture. 5th Annual Conference on Computational Science \& Computational Intelligence (CSCI'18), Dec 2018, Las Vegas, United States. 5p. hal-02015850

\author{
HAL Id: hal-02015850 \\ https://hal.laas.fr/hal-02015850
}

Submitted on 12 Feb 2019

HAL is a multi-disciplinary open access archive for the deposit and dissemination of scientific research documents, whether they are published or not. The documents may come from teaching and research institutions in France or abroad, or from public or private research centers.
L'archive ouverte pluridisciplinaire HAL, est destinée au dépôt et à la diffusion de documents scientifiques de niveau recherche, publiés ou non, émanant des établissements d'enseignement et de recherche français ou étrangers, des laboratoires publics ou privés. 


\section{A connected soil humidity and salinity sensor for precision agriculture}

\author{
Julien ROUX \\ LAAS-CNRS, S4M \\ Université de Toulouse, \\ CNRS, UT2J \\ Toulouse, France \\ jroux@laas.fr
}

\author{
Jean-Yves Fourniols \\ $L A A S-C N R S, S 4 M$ \\ Université de Toulouse, \\ CNRS, INSA \\ Toulouse, France \\ fourniols@laas.fr
}

\author{
Georges Soto-Romero \\ LAAS-CNRS, S4M \\ Université de Toulouse, \\ CNRS, INSA \\ Toulouse, France \\ gsotorom@laas.fr
}

\author{
Christophe Escriba \\ LAAS-CNRS, S4M \\ Université de Toulouse, \\ CNRS, INSA \\ Toulouse, France \\ cescriba@laas.fr
}

\begin{abstract}
The new methods for the agriculture have to improve the irrigation systems. Nowadays, an important part of irrigation water is wasted. A new connected agriculture needs to reduce that wastage by creating a sustainable agriculture. To achieve that goal, we need to control the soil moisture to perfectly adapt the water supply. This paper presents a new connected sensor to monitor in real time the irrigation impact on the fields. The challenges for this new system are the ease of installation, the cost and the network coverage. This work describes the design of this system and its results in fields.
\end{abstract}

Keywords-smart sensor, precision agriculture, bi-frequency sensor, sensor network

\section{INTRODUCTION}

The water consumption is a new challenge for the modern agriculture. Nowadays, water is wasted due to an overdose during the irrigation which is about 20\% [1]. These losses can be limited by a real-time monitoring of the soil [2]. In fact, few of agricultural exploitations are equipped with a monitoring system [3-4]. Moreover, the sensors deployed do not permit a real-time precise cartography of the soil state. First, some sensors used are tensiometers [5] which have a response time of several hours [6] and a phenomenon of false measurement, the uncoupling [7].

A new technology was developed to solve these problems and modernise the agricultural irrigation installations, the capacitive sensors [8-9]. The main advantage of this technology is a response time less than one minute which permits a real-time monitoring on the hydric state of the soil [10]. But their complex design [11-12] does not make them easy to use and deconstructs the soil when they are placed. Furthermore, with a special range of frequencies, soil capacity depends also on its ionic composition [13] which make possible the measure of soil salinity. The combination of these two measurement, moisture and salinity, can be obtain by only one sensor.

To break this design barrier, we based our design on an affordable capacitive sensor which are compatible with a large-scale deployment and an easy-to-use. First, this article presents the first design and its optimisation. Then, the electrical model of the sensor is described. The next section is the design of the on-board electronic for the associated measurement. Finally, the last section outlines the on-site results of performance tests.

\section{DESIGN OF THE CAPACITIVE SENSOR}

\section{A. First design : the capacitor}

Initially, design of the capacitive sensor is based on a basic capacitor. The structure is composed of two electrodes separated by a dielectric, the soil. A cylindrical shape is chosen to facilitate the soil insertion. The Fig. 1 presents this design.

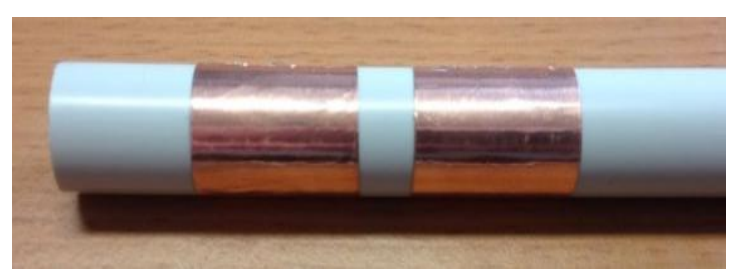

Fig. 1. First design of the sensor

The electrode thickness (less than $1 / 10 \mathrm{~mm}$ ) makes the capacity between the electrode along the tube negligible. A diameter of $20 \mathrm{~mm}$ is chosen to minimize the soil destruction at the soil insertion but to keep a solid resistance to breakages.

This article will not present the optimisation of the electrodes' dimensions. To assure a diameter of $20 \mathrm{~mm}$ for the final sensor, the capacitive part has to have a $17 \mathrm{~mm}$ diameter. Moreover, the sensor has electrodes of $25 \mathrm{~mm}$ of width separated by a space of $8 \mathrm{~mm}$, like it is shown on the Fig. 2.

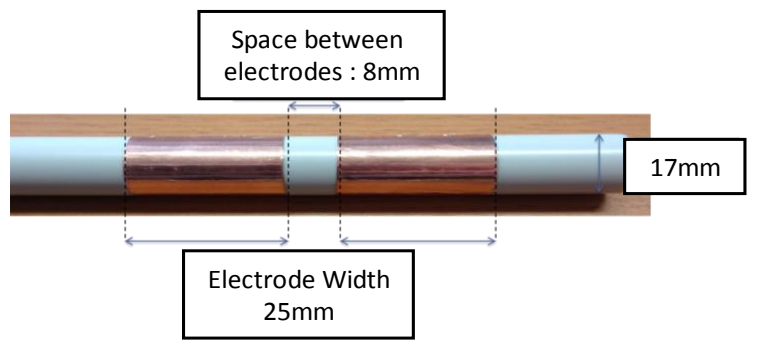

Fig. 2. Optimized capacitor design

Thanks to an analyser, the capacity of the sensor is measured for several soil moisture level. The Fig. 3 shows this compartmental response.

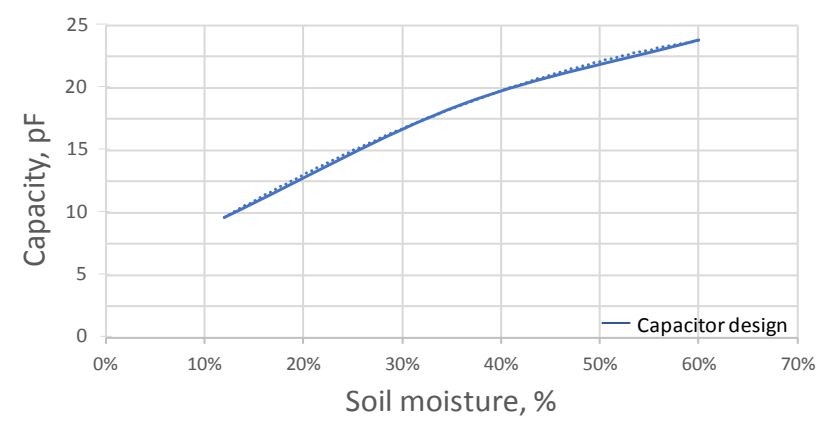

Fig. 3 : Capacity response of the capacitor design 
We can observe on this figure, an almost linear response of the sensor capacity. This comportment eases the signal processing needed in the electronic. We can observe also a variation of $12.6 \mathrm{pF}$ for a $48 \%$ change of moisture which gives a sensitivity of $0.26 \mathrm{pF} . \%^{-1}$.

Beyond the sensitivity, the volume of soil probed is necessary to be estimated. So, a COMSOL modelling of the final elements was carried out. The volume is quantified on the basis of the density of the electric field generated. The simulation shows a volume of $1.32 \mathrm{~L}$ probed with this design.

\section{B. New shapes with higher performance}

With the cylindrical shape having been optimized from a geometric as well as a technological point of view, we now focus on a more complete optimization of the sensitivity and/or the volume of the probed soil. To do so, we propose to optimize the electrodes' shape factor.

The first parameter to optimise is the sensitivity. The contact surface with the soil would determine the sensitivity of the sensor. But according to the cost limitation, the electrodes' surface cannot be increased for this sensor, it must be distributed along the full length of the cylinder. Inspired by the strands of DNA, the electrodes take the form of a double helix (left of the Fig. 4). The second parameter to optimise is the volume probed. This parameter depends on the electric field around the sensor. To increase its range, we distribute the electrodes in shape of branches diametrically opposed (right of the Fig. 4).
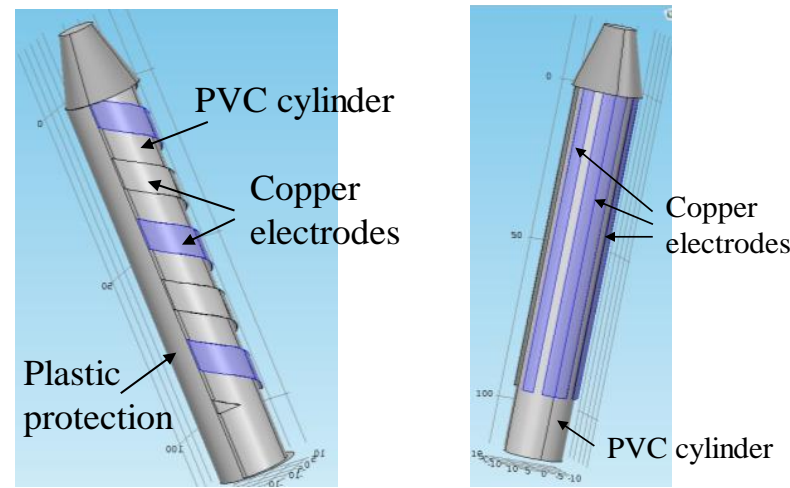

Fig. 4. New Shape designs

The Table 1 resumes the performance of the three design.

\begin{tabular}{|l|c|c|c|}
\hline $\begin{array}{c}\text { Electrode } \\
\text { Shape }\end{array}$ & $\begin{array}{c}\text { Sensitivity } \\
\left(\mathbf{p F} . \%^{-1}\right)\end{array}$ & $\begin{array}{c}\text { Linear } \\
\text { response }\end{array}$ & $\begin{array}{c}\text { Probed Soil } \\
(\mathbf{L})\end{array}$ \\
\hline Capacitor design & 0.265 & Yes & 1.32 \\
\hline Double helix & 0.4417 & Yes & 0.277 \\
\hline Branches & 0.7188 & No & 1.737 \\
\hline
\end{tabular}

The sensor with branches is not only more sensitive, $0.7188 \mathrm{pF} . \%^{-1}$, it also registers better soil volume, $1.737 \mathrm{~L}$. Clearly, its response is not linear, but this can be easily corrected with suitable measurement electronics. This shape is, therefore, the most suitable for our study. But, in terms of industrialisation, this shape also is the costliest due to the discontinuous character of the electrodes. Manufacturers agree that the cost of fabrication is two times higher, compared to cylindrical or helicoidal shapes. Costs limitations therefore prevailed over performance in the choice of a helicoidal shape for the sensor.

\section{MODELLING THE SENSOR}

\section{A. Frequency analysis}

Given the sensor's macroscopic capacitive behaviour, a spectral analysis is necessary to distinguish the useful frequency range. The first analysis (Fig. 5) compared different composition of soil to determine the salinity.

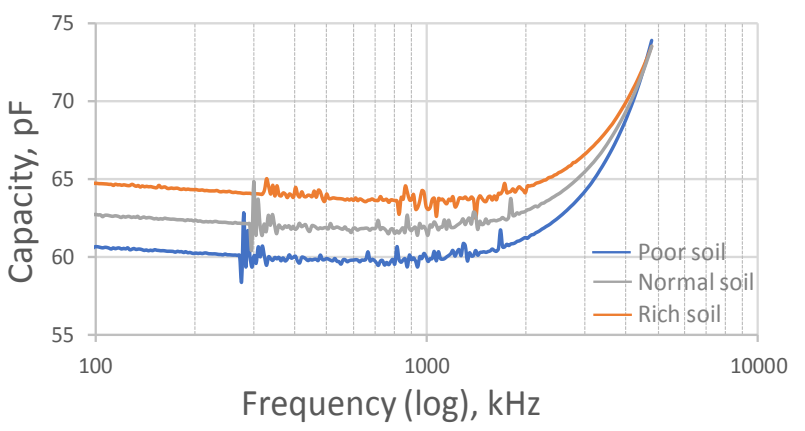

Fig. 5. Capacity according to the salinity

There is a limit (4 MHz) where above the salinity has no influence on the capacity. This means the moisture measurement is independent of the soil salinity. But below this limit, capacity increased with salinity. There are some perturbations below $300 \mathrm{kHz}$ so we can use the range $300 \mathrm{kHz}$ to $1 \mathrm{MHz}$ to measure the salinity.

We analyse now the comportment with the soil moisture by an analysis beginning at $1 \mathrm{MHz}$ (Fig. 6).

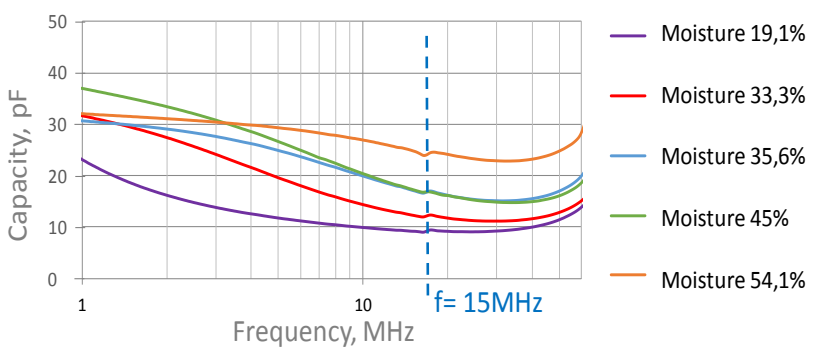

Fig. 6. Capacity according to moisture

This figure show that the capacity variations are inversely proportionate to moisture. Moreover, there is a capacity platform at about $15 \mathrm{MHz}$. Beyond this limit, an inductive parasitic effect is no longer negligible. The frequency to measure the moisture is limit between $1 \mathrm{MHz}$ and $15 \mathrm{MHz}$.

\section{B. Electrical Model}

Since sensor capacity is not perfect, we want to quantify the ESR, ESL and $\mathrm{C}_{\text {tube }}$ imperfections of the equivalent model. The Equivalent Series Resistor (ESR) is the resistance that materialises contact between the two electrodes, with a measured value of ESR $=105 \mathrm{~m} \Omega$. Equivalent Series Inductance (ESL) consists of the connecting wires that induce the inductive behaviour beyond $40 \mathrm{MHz}$. Measurements show that $\mathrm{ESL}=60 \mu \mathrm{H}$. Finally, inter-electrode capacity is equal to $\mathrm{C}_{\text {tube }}=5.18 \mathrm{fF}$. The Fig. 7 reflects this model. 


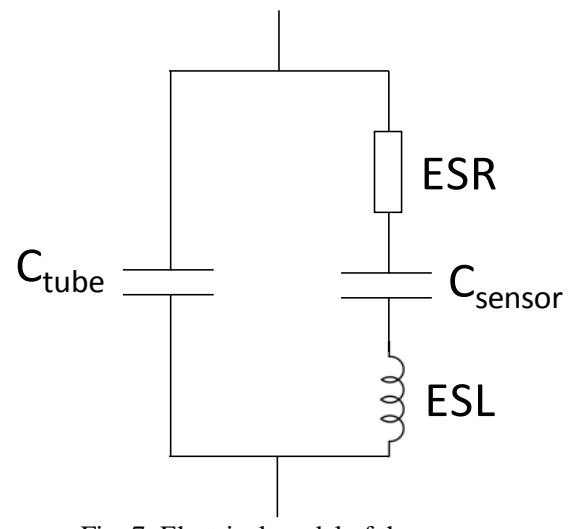

Fig. 7. Electrical model of the sensor

In the following of this study, all the parasitic effect (ESR, ESL and $\mathrm{C}_{\text {tube }}$ ) will be neglected.

\section{ON-BOARD ELECTRONIC}

\section{A. Architecture}

The architecture breaks down into two distinct parts (Fig. 8 ). The first part, the front end, permits the conversion of the sensor's capacity variations into one electric variation. Bearing in mind the frequency of readings and the low cost of the final system, the sensor is placed in a Colpitts oscillator to allow a capacity conversion frequency that depends on moisture or salinity. Since sensor must be able to perform two measurements, we decided to use two different oscillators set at $\mathrm{f}_{\mathrm{osc}}=8 \mathrm{MHz}$ for moisture and at $\mathrm{f}_{\mathrm{osc}}=$ $500 \mathrm{kHz}$ for salinity.

The back end, or second part of the architecture, delivers readings of the variations. To this end, the back end is structured around one microcontroller embedded with a frequency metre algorithm dedicated to double measurement of a frequency. To minimise the effect of temperature on the measurement, the microcontroller is equipped with a TCXOtype precision clock. To reduce the cost of the system, this microcontroller's frequency performances are voluntarily limited, which explains why the frequency is divided. Once this electronic treatment is accomplished, the back end proposes two types of complementary outlets, an analogue outlet that makes it possible to deliver voltage proportionate to moisture or to salinity with the aid of a CAN and a digital outlet that can be configured to establish a communications link with a standardised protocol (slave SPI).

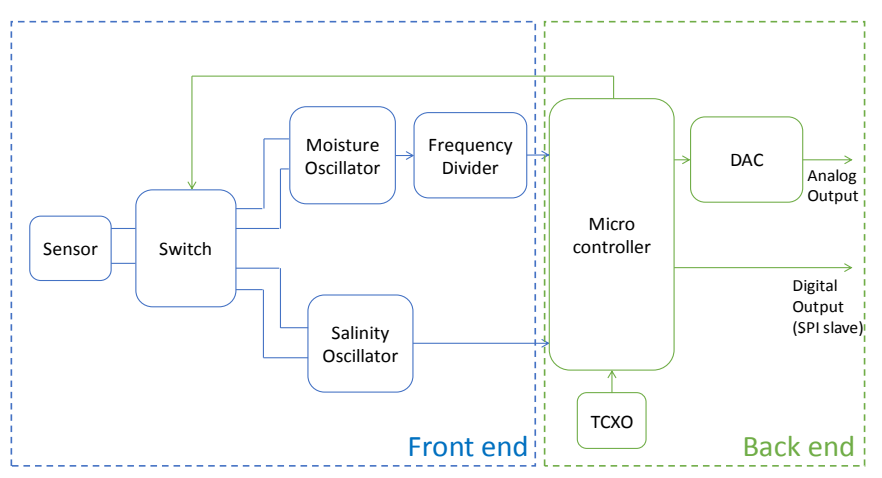

Fig. 8. Electronic architecture

\section{B. Integration}

In the process of industrial production of the sensor, the sensor tube will be manufactured according to an industrial procedure. The first stage consists of devising a cylindrical support tube. Then, the electrodes are produced according to photolithography and by electrochemical deposit of copper on a surface that has been made functional by a laser. Finally, a nickel/gold layer is deposited to protect the copper from oxidation. Since the sensor is to be inserted in the soil, it needs to be mechanically solid so that it is not damaged during its installation. As for the electronic board (Fig. 9), it is inserted in the sensor tube so that it forms a compact unit with no flexion points. To promote the mechanical longevity of the ensemble, recesses (Fig. 9) have been specifically sized.

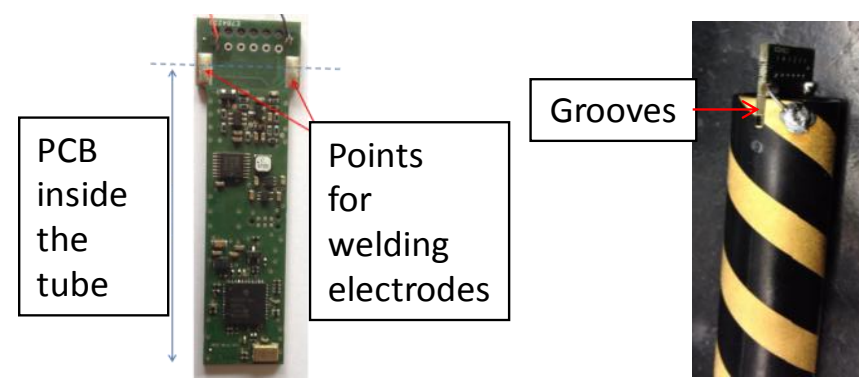

Fig. 9. Electronic integration

To permit power supply and communication with the system, a protective shield is directly soldered onto specific landing pads. Finally, the sensor's water tightness is ensured by an injection of plastic into a mould.

\section{To the final user}

With the aim of deploying the sensors in the cultivated fields, the architecture of the network is shown on Fig. 10. It makes it possible to ensure the transmission of moisture and salinity measurement readings to the user. This infrastructure was developed with the support of the TCSD company. This company markets systems that collect data for agriculture (weather and soil).

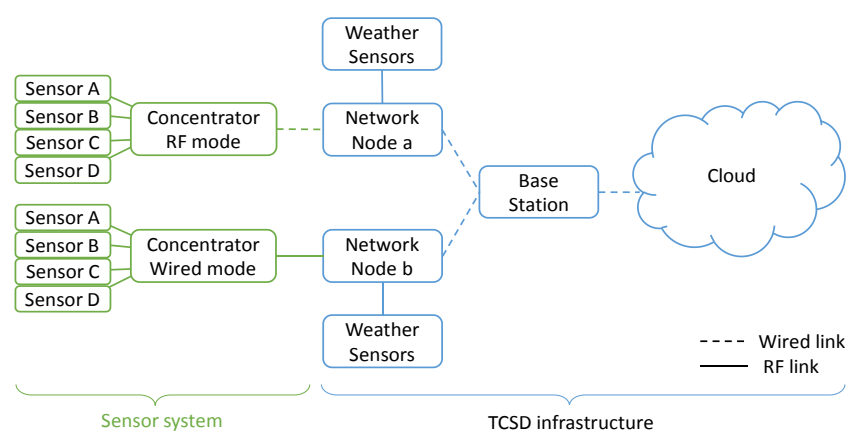

Fig. 10. Network architecture

The Fig. 10 reflects the different stages of data collection:

- A concentrator supervises four sensors. It then communicates this data by a wire connection with an SDI-12 protocol, either by a radiofrequency link on the ISM $868 \mathrm{MHz}$ band to allow total control of the exchange protocol. 
- Data then goes through the other network nodes that could be concentrators used in repeating mode or weather data collection points that also could serve as the bridge.

- Data finally arrive at a base station connected to the Internet, where information is stored on an on-line server. From then on, the user can consult the data by means of a web interface or mobile application.

\section{ON-SITE TESTS}

After the system is installed and deployed in cultivated and irrigated fields, moisture monitoring performance is compared to that of the major players in the market: Decagon. As this work continues, the sensor that we have developed is called IRRIS for IRRIgation Ingénierie Systèmes.

The Fig. 11 presents measurement readings in an orchard that is cultivated all year round. Data from the IRRIS sensor shown on the graphic reflect ten days of surveillance and are compared with that of the Decagon sensor.

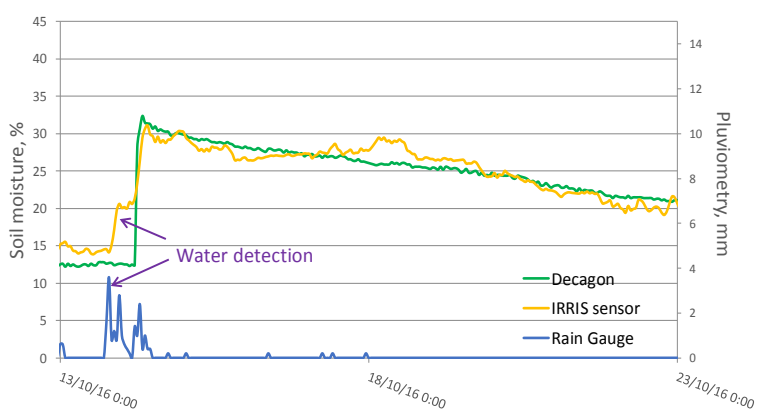

Fig. 11. On-site results comparing Decagon

The greater sensitivity of the IRRIS sensor is noticeable. As soon as the presence of water is detected by the IRRIS sensor, the moisture measurement increases, while the Decagon sensor does not detect this presence of water until after a few hours (purple arrows). Detection, therefore, is better with the IRRIS sensor. The rising dynamic $(+20 \%)$ and the descending dynamic ( $-2 \%$ per day) are identical for the two sensors, which validates the good performance of our sensor on this piece of agricultural land.

\section{CONCLUSION}

Using capacitive technology for our sensor, we develop a new smart sensor able to measure soil moisture and also soil salinity. For this purpose, double helix electrodes are formed to optimize the relationship between the sensor and the ground. Bases on Colpitts oscillator we develop an onboard electronic and a full digital signal processing to reduce cost. Regarding the humidity measurement, we obtain a sensor that has the same performance as the market leaders but for lower cost and a new functionality.

\section{ACKNOWLEDGMENT}

This work was done within the framework of the IRRIS project which is funded by the French Midi Pyrenees council and the French Ministry of Agriculture. Many thanks are due to TCSD (TelecommuniCation Service \& Distribution) who lead the project and helped us to deploy our system into actual agricultural exploitation. We would thank Gilbert SA for their industrial support and their advices for the mechanical integration.

\section{REFERENCES}

[1] A. Nabayi, C. B. S. Teh, A. H. Mohd Hanif, and Z. Sulaiman, "Plant growth, nutrient content and water use of rubber (Hevea brasiliensis) seedlings grown using root trainers and different irrigation systems," Pertanika Journal of Tropical Agricultural Science, vol. 41, pp. 251270, 2018.

[2] N. Sarkar, U. Ghosh, and R. K. Biswas, "Effect of drip irrigation on yield and water use efficiency of summer rice cultivation in pots," Journal of Pharmacognosy and Phytochemistry, vol. 7, no. 1, pp. 3740, Jan. 2018.

[3] A.-A. E. Pigford, G. M. Hickey, and L. Klerkx, "Beyond agricultural innovation systems? Exploring an agricultural innovation ecosystems approach for niche design and development in sustainability transitions," Agricultural Systems, vol. 164, pp. 116-121, Jul. 2018.

[4] E. Playán et al., "Assessing telemetry and remote control systems for water users associations in Spain," Agricultural Water Management, vol. 202, pp. 89-98, Apr. 2018.

[5] B. Faybishenko, "Tensiometer for shallow and deep measurements of water pressure in vadose zone and groundwater," Soil Science, vol. 165 , no. 6, p. 473, Jun. 2000.

[6] M. Hayashi, G. van der Kamp, and D. L. Rudolph, "Use of tensiometer response time to determine the hydraulic conductivity of unsaturated soil," Soil Science, vol. 162, no. 8, p. 566, Aug. 1997.

[7] C. M. Trotter, "Errors in reading tensiometer vacua with pressure transducers," Soil Science, vol. 138, no. 4, p. 314, Oct. 1984.

[8] T. J. Dean, J. P. Bell, and A. J. B. Baty, "Soil moisture measurement by an improved capacitance technique, Part I. Sensor design and performance," Journal of Hydrology, vol. 93, no. 1-2, pp. 67-78, Aug. 1987.

[9] H. O. Buckman and N. C. Brady, "The Nature and Properties of Soils," Soil Science, vol. 90, no. 3, 1960.

[10] F. Frasca, A. Caratelli, and A. M. Siani, "The capability of capacitive sensors in the monitoring relative humidity in hypogeum environments," IOP Conf. Ser.: Mater. Sci. Eng., vol. 364, no. 1, p. 012093, 2018.

[11] J. Boudaden et al., "Polyimide-Based Capacitive Humidity Sensor," Sensors, vol. 18, no. 5, p. 1516, May 2018.

[12] D. Xiao, J. Feng, N. Wang, X. Luo, and Y. Hu, "Integrated soil moisture and water depth sensor for paddy fields," Computers and Electronics in Agriculture, vol. 98, pp. 214-221, Oct. 2013.

[13] S. Visacro, R. Alipio, M. H. Murta Vale, and C. Pereira, "The Response of Grounding Electrodes to Lightning Currents: The Effect of Frequency-Dependent Soil Resistivity and Permittivity," IEEE Transactions on Electromagnetic Compatibility, vol. 53, no. 2, pp. 401-406, May 2011. 